\begin{tabular}{|c|c|c|}
\hline CanM产 & $\begin{array}{l}\text { Construction and Material Journal } \\
\text { e-ISSN 2655-9625,http://jurnal.pnj.ac.id/index.php/cmi }\end{array}$ & $\begin{array}{l}\text { Volume } 2 \text { No.1 } \\
\text { Maret } 2020\end{array}$ \\
\hline
\end{tabular}

\title{
ASESMEN, PERKUATAN DAN PERBAIKAN BANGUNAN NON- ENGINEERED PERUMAHAN MEKAR MELATI KELURAHAN LUBUK MINTURUN KOTA PADANG PASCAGEMPA 2009
}

\author{
Rafki Imani $^{*}$, , Sofia Anita ${ }^{2}$, Sonya Ostha Laurency ${ }^{3}$ dan Fakhru Rozi ${ }^{4}$ \\ 1,2,3,4 Universitas Putra Indonesia “YPTK” Padang, Jurusan Teknik Sipil, Jl. Raya Lubuk Begalung Kota \\ Padang, Sumatera Barat 25225 \\ *)e-mail : rafki_imani@upiyptk.ac.id
}

\begin{abstract}
The West Sumatra Earthquake on September 30, 2009, which also hit Padang City, caused most of the buildings to be severely and slightly damaged. This paper discusses the types of damage, repairs and reinforcement of residential houses in Mekar Melati Housing, Lubuk Minturun Sub-District, Padang City, West Sumatra. Data were collected using direct survey and assessment on both houses that have been severely damaged or slightly damaged. After the 2009 earthquake, the residential houses in the Mekar Melati housing complex in Lubuk Minturun, generally suffered severe damage and slight damage. The reason is that the building there is included in the category of very simple houses. Building materials used without slof, let alone walls that only use hollowbrick material, of which if the material is not plastered it will become brittle, resulting in the building easily collapsing.
\end{abstract}

Keywords: Damage, earthquake, residential houses, repairs and reinforcement.

\section{ABSTRAK}

Gempa Sumatera Barat pada 30 September 2009 yang turut melanda Kota Padang telah mengakibatkan sebagian besar bangunan mengalami rusak berat dan ringan. Makalah ini membahas jenis kerusakan, perbaikan dan perkuatan bangunan rumah warga di Perumahan Mekar Melati Kelurahan Lubuk Minturun Kota Padang, Sumatera Barat. Pengambilan data dilakukan dengan survei dan asesmen secara langsung, baik rumah yang mengalami rusak berat maupun rusak ringan. Pascagempa 2009 bangunan rumah warga di perumahan Mekar Melati Kelurahan Lubuk Minturun, umumnya banyak mengalami rusak berat dan juga rusak ringan. Penyebabnya adalah karena bangunan di sana termasuk kategori rumah yang sangat sederhana (RSS). Material bangunan yang digunakan tidak memakai slof, apalagi dinding yang hanya menggunakan bahan hollowbrick, dimana bahan tersebut jika tidak diplaster maka akan menjadi rapuh sehingga mengakibatkan bangunan mudah runtuh.

Kata kunci : Kerusakan, gempa bumi, perumahan, perbaikan dan perkuatan.

\section{PENDAHULUAN}

Posisi Kota Padang yang berada di atas lempeng Indo-Australia dan Eurasia telah menempatkan Kota Padang rawan terhadap gempa tektonik. Gempa 2009 Sumatera Barat adalah gempa besar yang pernah terjadi di Indonesia dan berpusat sekitar $50 \mathrm{~km}$ Barat Laut Kota Padang [1]. Gempa ini telah menyebabkan kerusakan pada fisik bangunan dan berpotensi terjadinya tsunami. Gempa yang terjadi merupakan jenis gempa laut yang dapat mengakibatkan gelombang tsunami.

Beberapa wilayah di Kota Padang telah mengalami kerusakan bangunan termasuk bangunan di Perumahan Mekar Melati, Kelurahan Lubuk Minturun. Tingkat kerusakan rumah warga di lokasi ini mulai dari rusak ringan bahkan hingga rusak berat. Sampai saat ini, setelah lebih dari satu dekade, masih saja ditemukan adanya rumah warga yang belum melakukan perbaikan struktur dan masih diperlukan 
penyuluhan perkuatan bangunan agar ramah gempa, sehingga risiko gempa yang mungkin akan terjadi di masa mendatang masih menjadi ketakutan bagi sebagian warga yang bermukim di sana.

\section{DASAR TEORI}

Bencana alam umumnya banyak menimbulkan kerusakan, khusunya bencana gempabumi, dimana telah sering membuat bangunan rusak dan juga dapat meruntuhkan [3]. Gempabumi adalah getaran alamiah yang terjadi di permukaan tanah, yang menimbulkan goncangan. Goncangan ini dapat diukur dengan skala yang dikenal dengan skala intensitas (Mercalli Modified Intensity, MMI) [4].

Setelah terjadi gempa banyak sekali bangunan dan perumahan warga yang hancur. Kerusakan yang terjadi akibat gempa dapat dibedakan menjadi dua yaitu kerusakan berat dan kerusakan ringan. Kerusakan berat seperti plesteran pada dinding terlepas, dinding bata retak atau pecah, plafon rusak, serta runtuhnya bangunan. Sedangkan kerusakan ringan adalah kerusakan yang terjadi pada elemen struktur bangunan, seperti retak pada bagian kolom, pelat atau balok, terlepasnya selimut beton balok/kolom atau pecahnya bagian kepala atau bawah kolom.

\section{Kategori Struktur dan Kerusakan Bangunan}

Struktur bangunan dikelompokkan menjadi non-engineered building dan engineered building. Non engineered building merupakan bangunan sederhana yang pembangunannya tidak dilakukan oleh ahli struktur, sementara engineered building merupakan bangunan yang direncanakan dan dilakukan perhitungan struktur dengan baik oleh konsultan.
Kerusakan yang terjadi akibat gempa dapat dibedakan atas kerusakan nonstruktural dan kerusakan struktural. Kerusakan non-struktural merupakan kerusakan yang terjadi pada bagian nonstruktur bangunan seperti plasteran dinding terlepas, dinding bata retak atau pecah dan plafon yang rusak. Kerusakan struktur merupakan kerusakan yang terjadi pada elemen utama struktur bangunan, seperti retak pada bagian kolom, pelat atau balok, terlepasnya selimut beton balok/kolom atau pecahnya bagian kepala atau bawah kolom [5], seperti Gambar 2. Pada Gambar 2 terlihat kerusakan struktural rumah warga akibat gempa, dimana kerusakan tersebut terjadi karena terdapat detailing penulangan yang tidak baik.

\section{Perbaikan Struktur Bangunan}

Perbaikan dan perkuatan perumahan pasca gempa dikenal juga dengan istilah retrofitting yang meliputi pekerjaan perbaikan (repair), restorasi (restoration) dan perkuatan (strengthening) pada suatau perumahan yang mengalami kerusakan. Pekerjaan perbaikan (repair) adalah pekerjaan yang mengembalikan bentuk arsitektur perumahan sehingga dapat berfungsi kembali dengan baik, serta melakukan pembangunan ulang dari awal pada bangunan yang mengalami rusak berat, dan sebagian kecil juga melakukan penambalan retak-retak pada bangunan yang mengalami rusak ringan [7].

Pekerjaan restorasi (restoration) adalah pekerjaan dengan tujuan untuk memperbaiki komponen-komponen struktur penahan beban dan mengembalikan pada kekuatan semula, tetapi di perumahan Lubuk Minturun Kota Padang ini masih sangat banyak kondisi rumahnya belum mengalami perubahan/perbaikan dari pemilik rumah karena rumah masih banyak yang belum ditempati oleh pemiliknya. 
Namun ada juga beberapa yang melakukan injeksi semen grout atau bahan epoxy ke dalam retak-retak kecil yang terjadi pada dinding pemikul, tulangan yang dipakai 6,4 (K9 9 kolom, balok) dengan jarak sengkang $(25 \mathrm{~cm}$ $35 \mathrm{~cm})$. Pekerjaan perkuatan (strengthening) adalah pekerjaan dengan tujuan untuk membuat perumahan menjadi lebih kuat dari kekuatan semula. Dalam makalah ini dibahas sebab-sebab kerusakan, perkuatan dan perbaikan yang dilakukan pada sejumlah perumahan warga di lokasi penelitian yang rusak pascagempa 2009 silam.

\section{METODE PENELITIAN}

Pengambilan data dalam penelitian ini dilakukan secara langsung dengan mendatangi wilayah Kelurahan Lubuk Minturun Perumahan Mekar Melati Kota Padang (Gambar 3) [8], dan melakukan pendataan terhadap rumah warga yang terkena gempabumi Sumatera Barat 2009. Data diambil dengan cara melakukan survei pada beberapa rumah yang pernah terkena dampak gempa di lokasi penelitian. Data yang diambil meliputi data perkuatan dan perbaikan serta mutu bahan (beton dan baja tulangan), Kota Padang, Sumatera Barat.

\section{HASIL dan PEMBAHASAN}

Kategori Perumahan Mekar Melati di Kelurahan Lubuk Minturun merupakan perumahan yang hanya menggunakan pondasi dangkal, struktur tanah bekas dari pertanian sawah (kategori tanah lunak) (Wawancara dengan Bapak Jon Rizal, 2019), seperti pada Gambar 4. Perbaikan dan perkuatan pada perumahan yang rusak dilakukan dengan mengulang kembali seluruh bagian rumah mulai dari dasar sampai akhir pembangunannya. Disamping itu ada juga yang melakukan perbaikan sekedarnya bahkan ada yang membiarkan bangunan rumahnya setelah rusak akibat gempa 2009 hingga sekarang.

\section{Kategori Struktur dan Kerusakan Bangunan}

Dari hasil survei yang dilakukan pada sejumlah bangunan yang rusak di Kota Padang tepatnya di Kelurahan Lubuk Minturun pascagempa 2009 silam, serta hal-hal yang menyebabkan beberapa bangunan tersebut tidak ramah gempa yang terjadi pada tahun 2009 karena masalah bantuan yang sulit sehingga pembuatan kolom tidak sesuai dengan aturannya. Disamping itu masalah sosialisasi yang tidak terlaksana dengan baik kepada masyarakat. Berikut beberapa kerusakan bangunan yang berada di wilayah Lubuk Minturun akibat gempa 2009.

Gambar. 9 menunjukkan dinding yang tidak menggunakan balok pinggang juga akan berpengaruh kepada kudakuda rumah, akibatnya dinding rumah menjadi miring dan tidak menyatu dengan kuda-kuda rumah sehingga jika tidak dilakukan perbaikan maka bisa berakibat fatal [9].

\section{a. Penulangan yang Tidak Sesuai dengan Aturan yang Terjadi pada Sambungan Antara Balok dan Kolom}

Dalam hal tersebut penggunaan kolom dan balok sangat berpengaruh terhadap kekuatan dan ketahanan rumah, serta kenyamanan yang akan dinikmati oleh penghuni rumah terhadap bencana yang akan terjadi seperti gempa, hal yang harus diperhatikan dalam pembuatan kolom dan balok yaitu ukuran besi dan jarak antara ring yang mengikat besi pada pembuatan kolom, dan penggunaan agregat yang sesuai untuk pembuatan kolom dan balok.

Pada Gambar 5, Penulangan kolom dan balok tidak mengikuti standar. Perletakan kolom utama yang 
disarankan jaraknya antara kolom yang satu dengan yang lain adalah 3,5 m agar penopang lantai tidak begitu besar, sedangkan pada rumah di Gambar 5 lebih dari 3,5 m [7].

Pada Gambar. 6, terlihat kolom dan balok tidak menyatu dan menerus dengan baik akibat dari pencampuran bahan tidak seimbang antara pasir, semen, dan split, yang hanya menggunakan pekiraan saja, yang belum tentu sesuai dengan aturan dalam pembuatan kolom dan balok, dan mutu bangunan juga bepengaruh terhadap perkuatan dan ketahanan bangunan. Secara keseluruhan berdasarkan Gambar 6, bahwa banyak yang tidak sesuai dengan bahan yang telah ditentukan oleh standarisasi SNI [10].

\section{b. Bangunan Tidak Menggunakan Sloof}

Sloof merupakan bagian dari struktur yang terletak antara pondasi dan dinding berguna agar meratakan beban pondasi, dan sebagai pengunci dinding agar apabila terjadi pergerakan tanah, dinding tidak sampai roboh. Sloof juga merupakan struktur yang penting dalam bangunan. Dalam hal ini penggunaan kolom dan balok sangat berpengaruh terhadap kekuatan dan ketahanan rumah, serta kenyamanan yang akan dinikmati oleh penghuni rumah terhadap bencana yang akan terjadi.

Gambar. 7 di atas terlihat dinding yang hampir roboh akibat gempa 2009, penyebabnya karena tidak menggunakan sloof pada bangunan tersebut, sehingga kekuatan dan ketahanan dinding berkurang karena tidak adanya perkuatan dari sloof [7].

\section{c. Bangunan Tidak Menggunakan Balok Pinggang}

Balok pinggang berfungsi untuk rumah yang ramah gempa dan mengakibatkan dinding rumah tahan akan bencana, berguna menambah ketahanan dinding agar tidak mudah roboh serta pengikatan kolom yang bertambah dengan ditambahkannya balok pinggang serta cocok digunakan untuk daerah yang rawan gempa, seperti Kota Padang.

Penggunaan balok pinggang sangat berguna bagi bangunan yang berada di daerah rawan gempa. Gambar. 8 di atas merupakan dinding yang belum ada sama sekali melakukan perbaikan dan ini merupakan akibat dari tidak menggunakan balok pinggang, dan adanya penggunaan hollwobrick sehingga ketahanannya tidak kuat untuk daerah rawan gempa.

\section{Perbaikan dan Perkuatan Elemen Struktur Bangunan}

Dalam hal perbaikan rumah yang dilakukan oleh warga kelurahan lubuk minturun akbat dari gempa yang terjadi pada tahun 2009, warga dari daerah kelurahan lubuk minturun mendapatkan bantuaan dari pemerintah sebanyak \pm Rp 15.000.000 untuk setiap rumah dalam kategori rusak berat. Berikut merupakan beberapa bangunan yang telah diperbaiki.

Perbaikan yang dilakukan oleh salah seorang warga yaitu memperbaiki bagian yang rusak saja dan tidak merubah kedudukan rumah tersebut ke arah yang lebih baik seperti menambahkan kolom lagi dengan jarak kolom yang satu dengan yang lain 3,5 m, dan diberi dimensi kolom praktis $15 / 15$ dengan tulang beton $4 \mathrm{D} 10$, begel D8-20, sedangkan untuk lantai 2 biasanya dipakai ukuran 20/20, dengan tulang pokok 8 D12, dan begal D8-10 $\mathrm{cm}$.

Dalam hal ini warga sudah mulai banyak yang menambahkan balok pinggang pada dinding rumah yang 
akan mereka buat agar tidak terjadi sesuatu yang tidak diinginkan dan mungkin masih ada beberapa warga yang masih kurang kesadarannya akan pentingnya kekokohan dari rumah atau bangunan dengan ditambahkannya balok pinggang yang perkerjaannya sama dengan pembuatan balok biasa, dan yang membedakannya hanya letaknya yang berada di tengah-tengah dinding.

\section{KESIMPULAN}

Bangunan rumah warga di Perumahan Mekar Melati Lubuk Minturun umumnya masih berupa tipe rumah sangat sederhana, sehingga banyak bangunannya dibangun seadanya. Selain itu, kurangnya sosialisasi dilakukan di daerah penelitian terkait kualitas struktur bangunan, sehingga masih banyak warga yang membangun rumah terkesan asal-asalan. Secara umum, masih banyak rumah warga yang belum menunjukkan kesadaran akan pentingnya perbaikan dan perkuatan bangunan ramah gempa, khususnya pascagempa Sumatera Barat 2009 silam.

\section{DAFTAR PUSTAKA}

[1] W. Setyonegoro, "Gempabumi Padang 30 September 2009 dan Potensi Tsunaminya," Buletin Meteorologi Klimatologi dan Geofisika, Vol. 7 No. 3, Research and Devolepment Center BMKG,
ISSN: 0215-1952, Jakarta, September 2013.

[2] Artikel online, tersedia di: https://dokumen.tips/download/link /proposal-penelitian-evaluasikinerja-struktur.

[3] T. Boen, "Gempabumi," Jakarta: UGM Press, 2013.

[4] S.L. Kramer, "Geotthecnical Earthquake Engineering," Peason, United States of America, 2014.

[5] T. Boen, "Cara memperbaiki Bangunan Sederhana yang Rusak Akibat Gempa Bumi, Cetakan Kedua, WSSI, 2010.

[6] Online: https://www.pikiranrakyat.com/jawa-barat/pr01290944/korban-gempatasikmalaya-butuhkan-bahanpangan-dan-terpal-416068.

[7] Zaidir, Fauzan, A. Hakam, F. A. Ismail, "Perbaikan dan Perkuatan Bangunan Pasca Gempa Sumatera Barat Tahun 2009," Prosiding PIT ke-5 Riset Kebencanaan IABI Universitas Andalas, Mei 2018.

[8] Google Maps, online: https://www.google.com/maps/sear ch/perumahan+mekar+melati+lubu k+minturun+kota+padang/. 2019

[9] A. S. Arya, T. Boen, Y. Ihiyama, 2013, Guidelines for Earthquake Resistant Non-Engineered Construction

[10] Fauzan, Zaidir, M.P. Laura, 2010, Analisa kegagalan Struktur dan Perkuatan (Retrofitting) Kolom Gedung B SMA N 10 Padang yang rusak akibat Gempa 30 September 2009", Jurnal Teknika ISSN : 0854-8471, No. 34, Vol 1 
Rafki Imani, Perkuatan, Perbaikan dan...

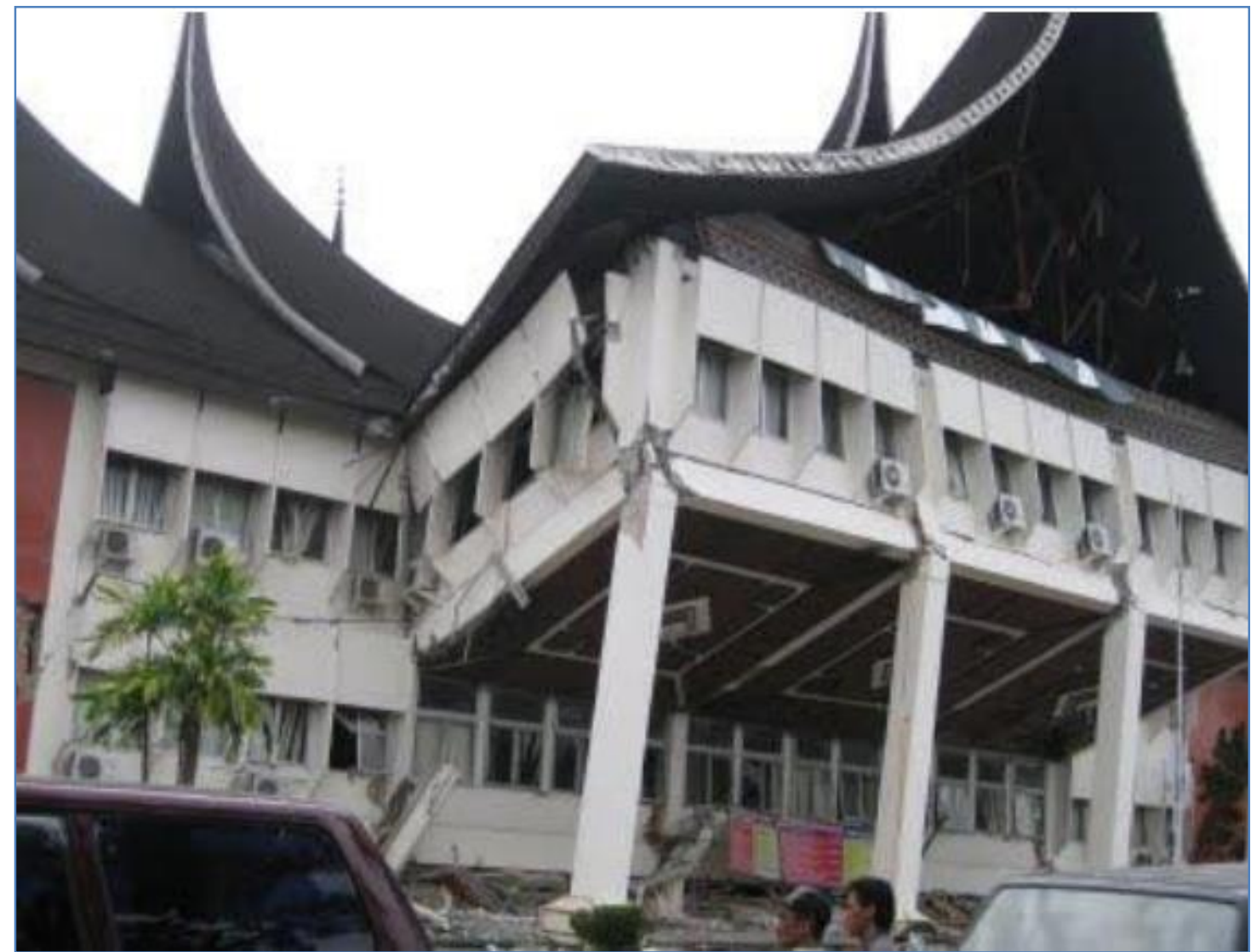

Gambar 1. Keruntuhan bangunan publik akibat gempa 2009 [2].

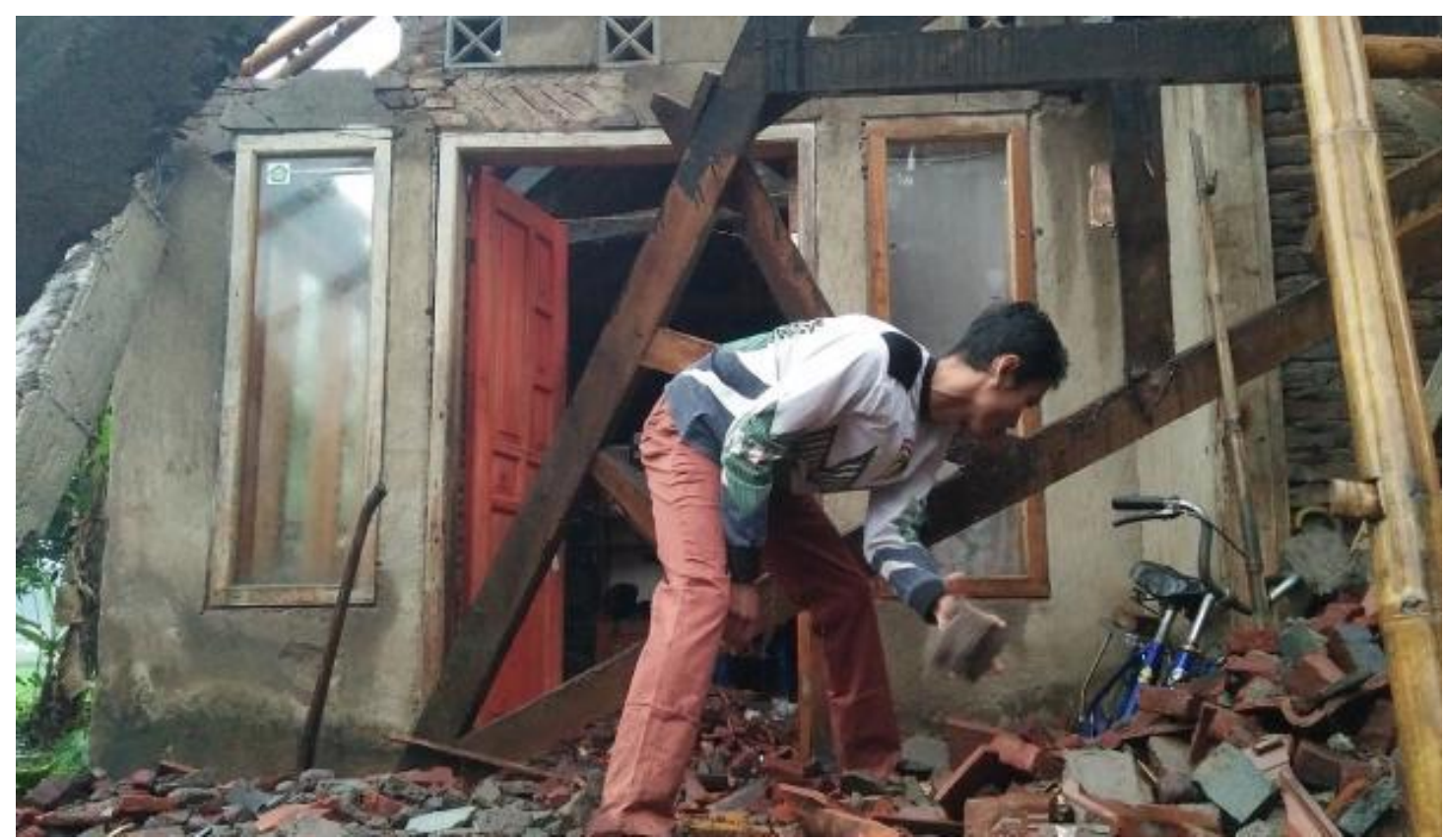

Gambar 2. Kerusakan bangunan rumah warga akibat gempa [6]. 


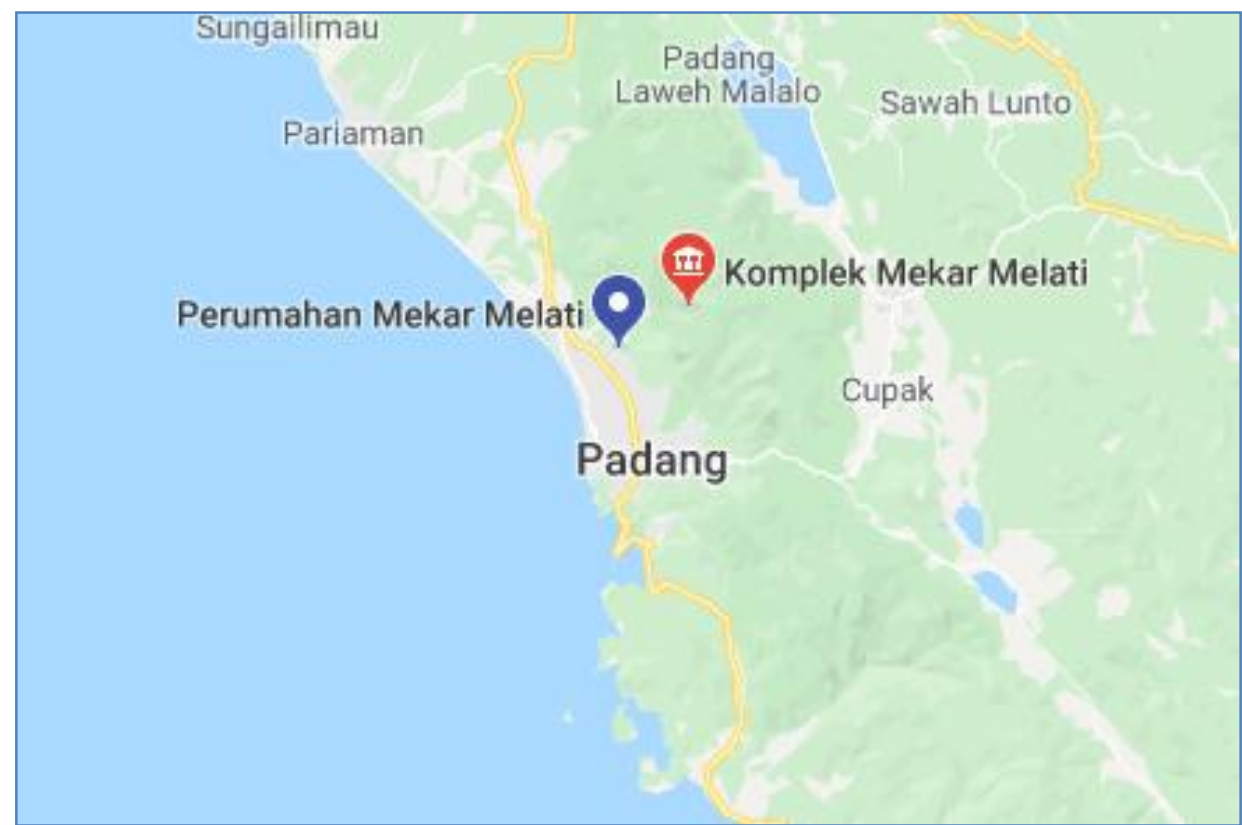

Gambar 3. Lokasi penelitian [8].

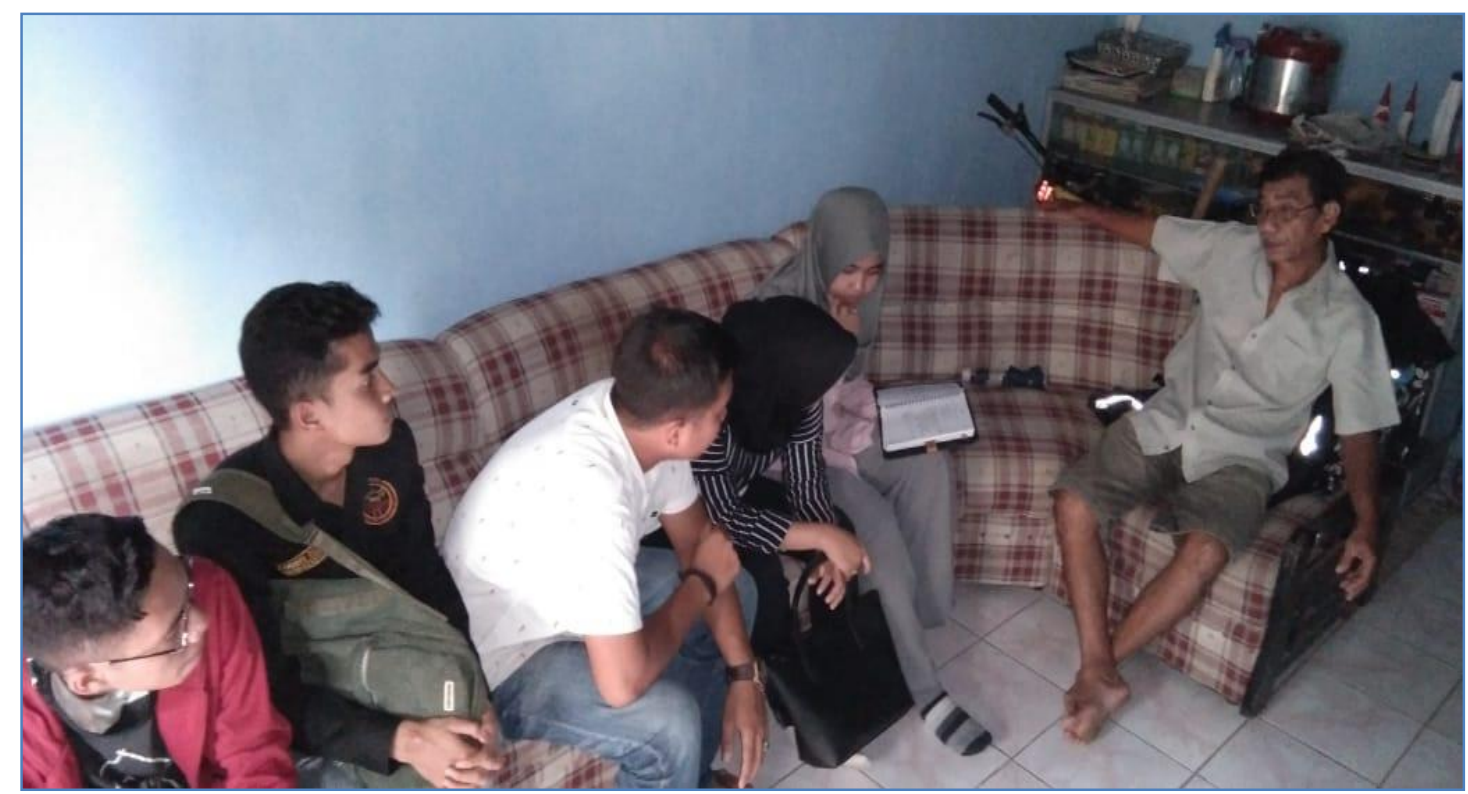

Gambar 4. Pengumpulan data melalui wawancara dengan salah satu responden. 


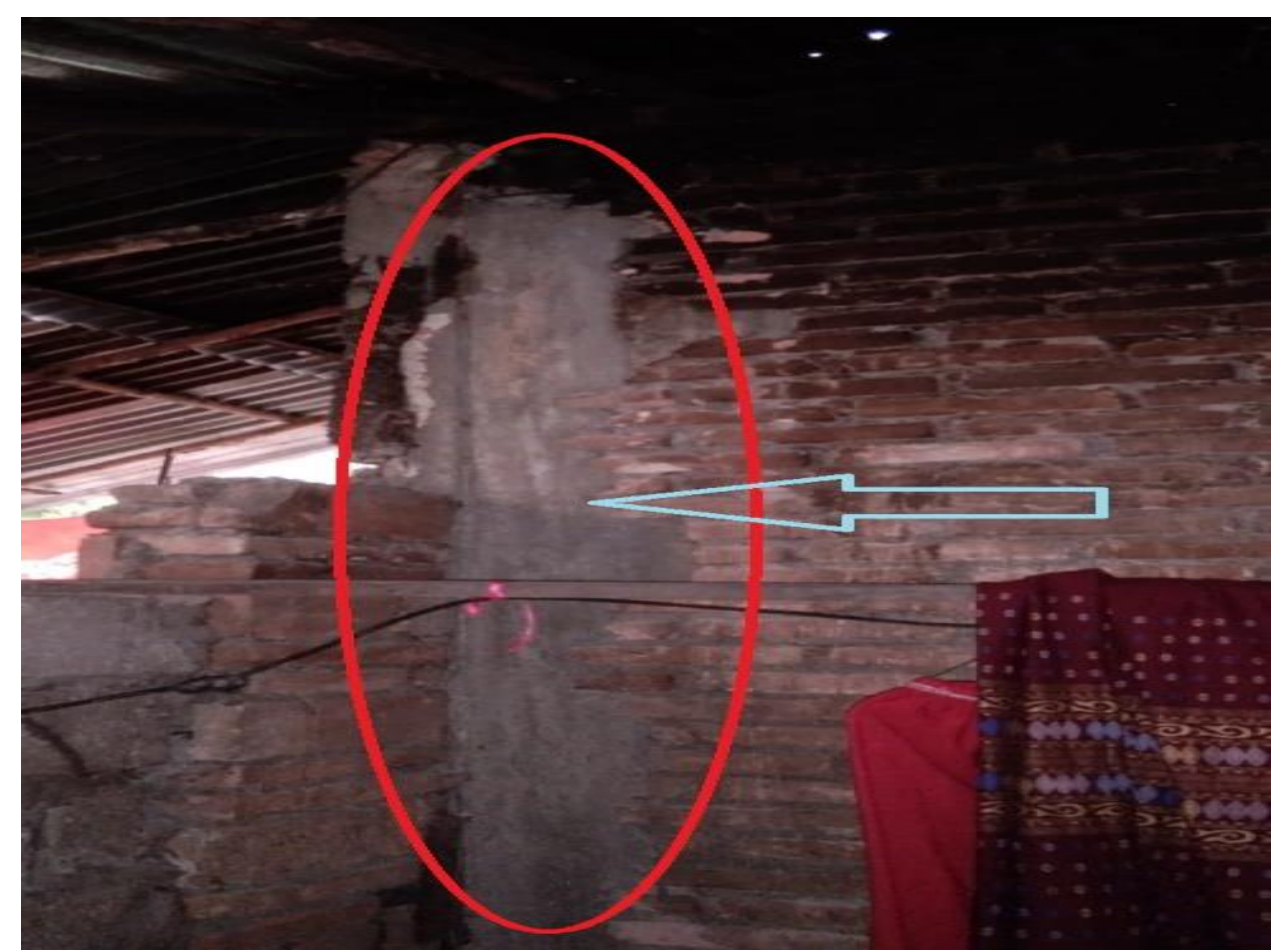

Gambar 5. Penulangan balok dan kolom yang salah.

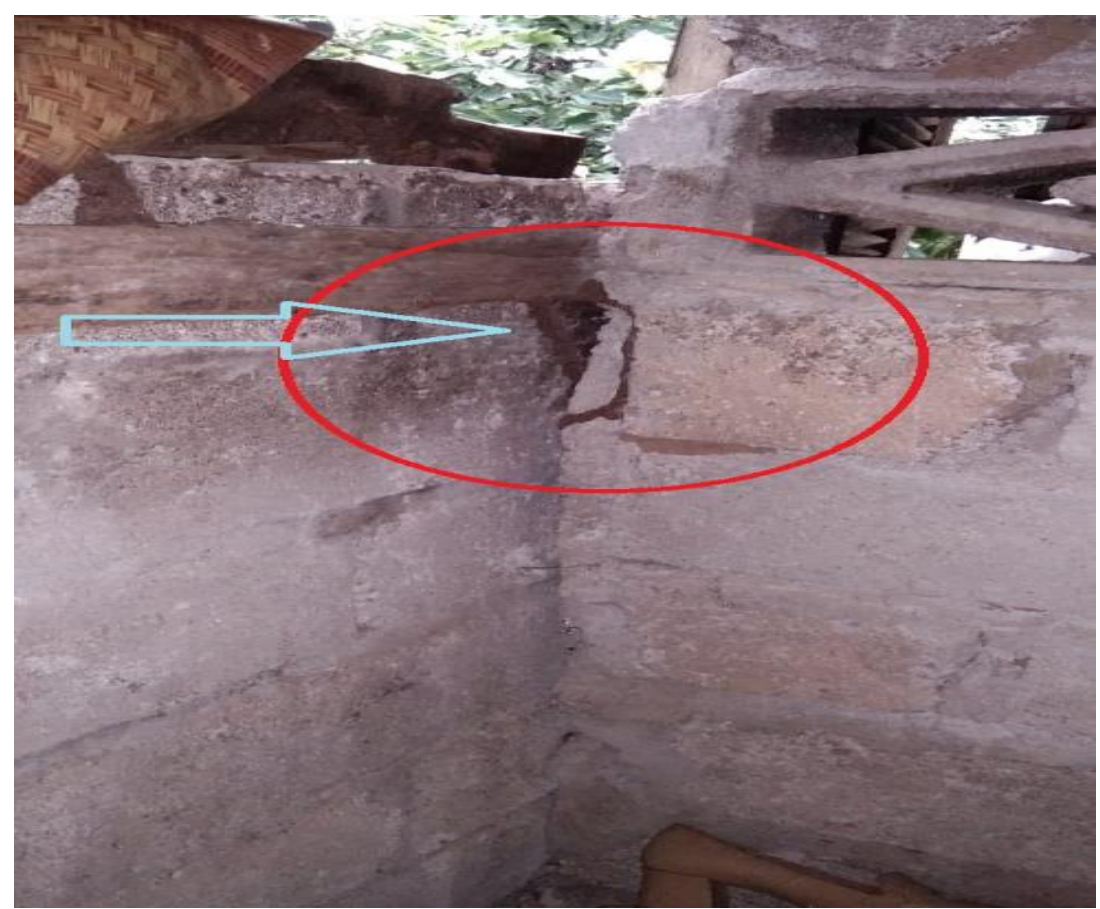

Gambar 6. Kolom dan balok tidak menerus. 


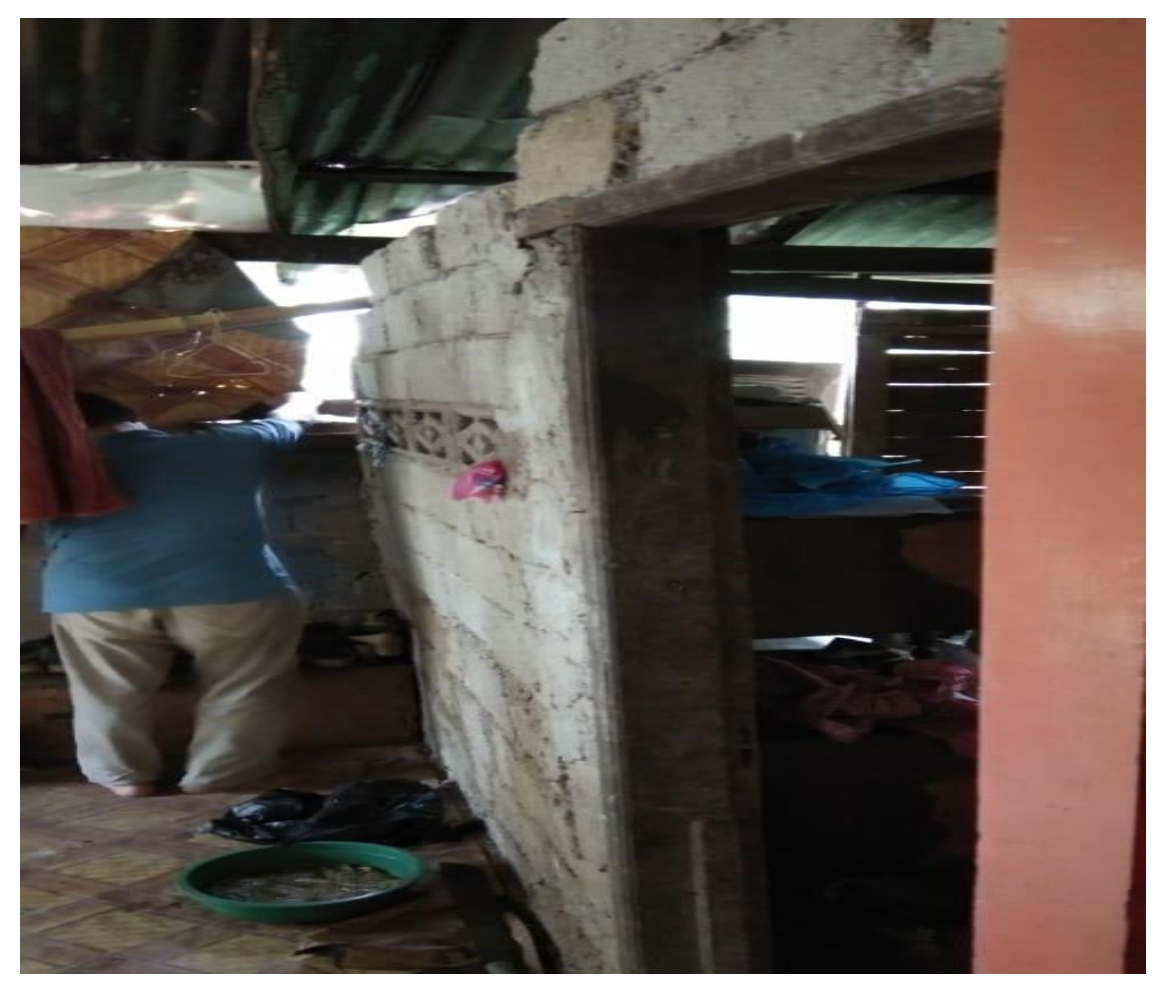

Gambar 7. Kerusakan struktur utama akibat tidak menggunakan sloof.

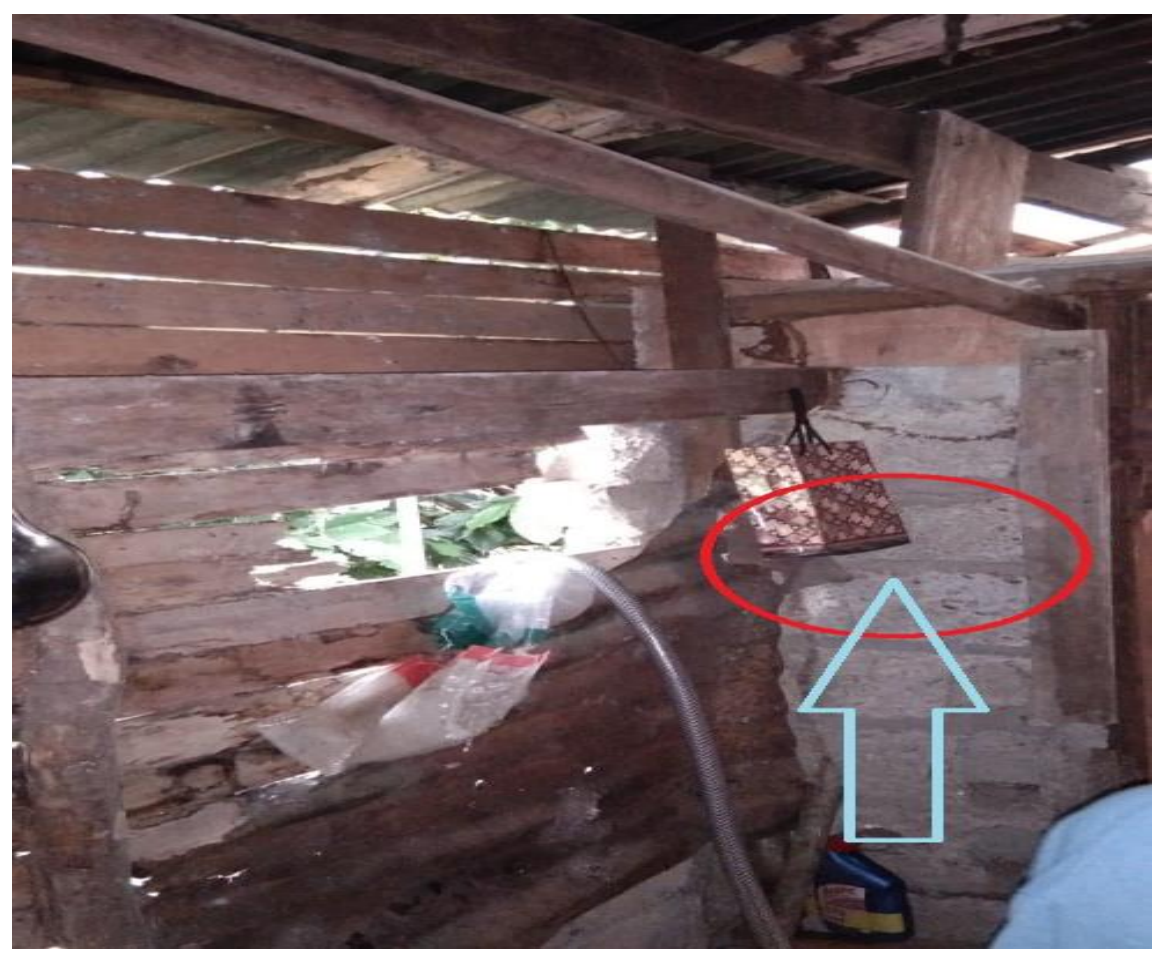

Gambar 8. Kerusakan dinding dapur tanpa balok pinggang. 


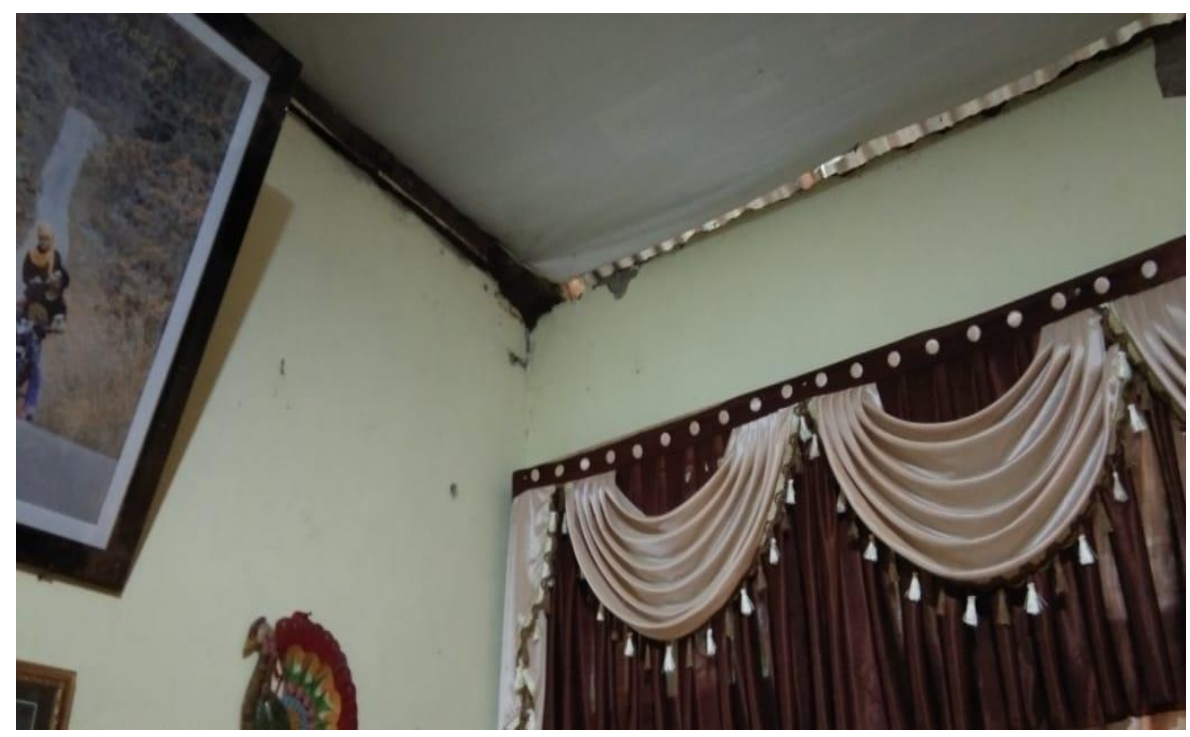

Gambar 9. Dinding yang tidak menyatu dengan kuda-kuda rumah.

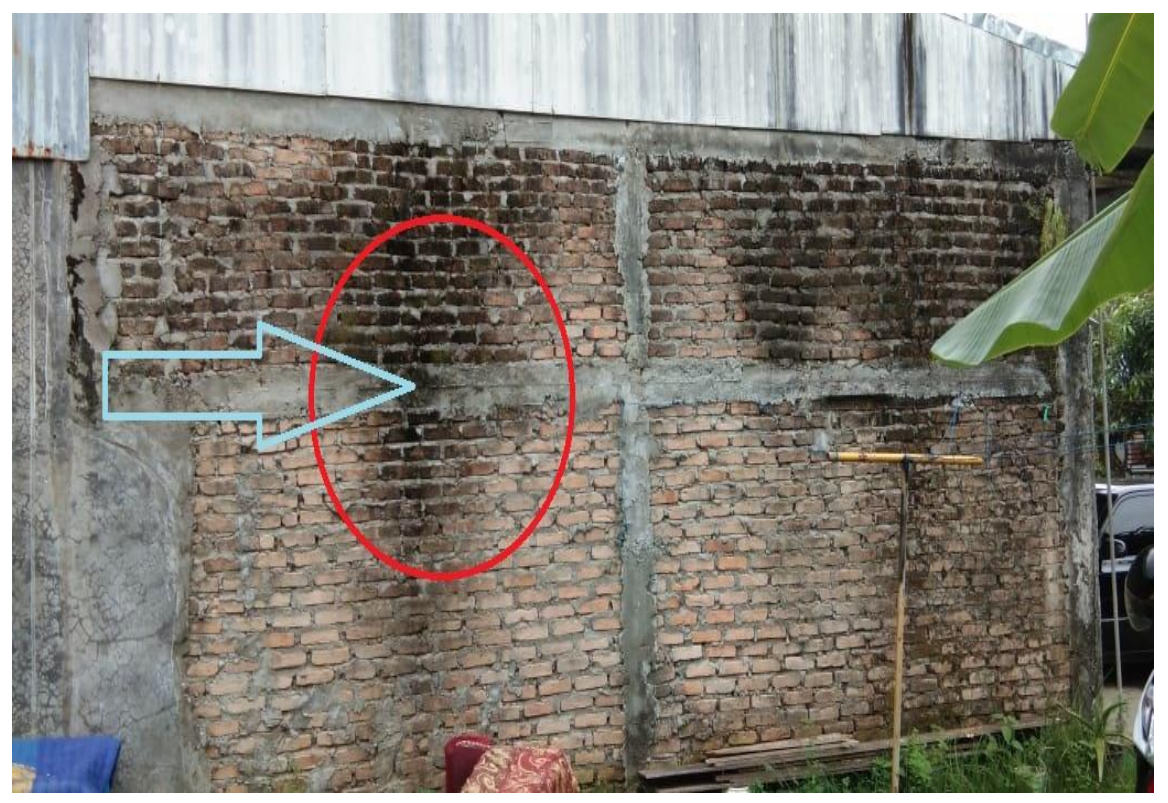

Gambar 10. Penambahan balok pinggang pada dinding. 